\title{
Study of Copper(II) Polyazamacrocyclic Complexes by Electronic Absorption Spectrophotometry and EPR Spectroscopy
}

\author{
Carlos F. G. C. Geraldes, ${ }^{*[a]}$ M. Paula M.Marques, ${ }^{[b]}$ Baltazar de Castro, ${ }^{*[c]}$ and \\ Eulália Pereira ${ }^{[\mathrm{c}]}$
}

Keywords: Macrocyclic ligands / Copper / EPR spectroscopy / Electronic spectrophotometry

Copper(II) mononuclear complexes with the polyazamacrocyclic ligands NOTA (1,4,7-triazacyclononane- $N, N^{\prime}, N^{\prime \prime}-$ triacetate), DOTA $(1,4,7,10$-tetraazacyclo-dodecane$N, N^{\prime}, N^{\prime \prime}, N^{\prime \prime \prime}$-tetraacetate), NOTP $[1,4,7$-triazacyclononane$N, N^{\prime}, N^{\prime \prime}$-tris(methylenephosphonate)] and DOTP $[1,4,7,10$ tetraazacyclododecane- $N, N^{\prime}, N^{\prime \prime}, N^{\prime \prime \prime}$-tetrakis(methylenephosphonate)] were characterised in aqueous solution by electronic absorption spectrophotometry and electron paramagnetic resonance (EPR) spectroscopy. While two isomeric species were detected by EPR spectroscopy in frozen samples of the polycarboxylate complexes, only one complex form was found for the poly(methylenephosphonate) systems. The results obtained are in accordance with a six-coordinate pattern for the metal centre, yielding tetragonally distorted complexes in solution, in agreement with previously reported studies on $\mathrm{Cu}^{\mathrm{II}}$ complexes, both in solution and in the solid state.

\section{Introduction}

In the past two decades there has been a growing interest in the study of metal complexes with macrocyclic polyfunctional ligands, as they have found use in a wide variety of applications, ranging from analytical chemistry ${ }^{[1-4]}$ to biochemistry and medicine. ${ }^{[5-7]}$ A knowledge of the conformational preferences of these systems in aqueous solution is thus of the utmost importance in predicting their coordination behaviour and understanding their mechanism of action.

Among the numerous macrocyclic ligands known, the coordination chemistry of many transition metal ions with the $N$-substituted polyazamacrocycles NOTA (1,4,7-triazacyclononane- $N, N^{\prime}, N^{\prime}$ '-triacetate), DOTA $(1,4,7,10$-tetraazacyclododecane- $N, N$,,$N$ ', $N$ '"'-tetraacetate), NOTP [1,4,7-triazacyclononane- $N, N$ ', $N$ '"-tris(methylenephosphonate)] and DOTP $\left[1,4,7,10\right.$-tetraazacyclododecane- $N, N, N^{\prime}, N^{\prime \prime}$-tetrakis(methylenephosphonate)] (Figure 1), due to their remarkable chelating properties, has been the object of numerous studies. Complexes of the above ligands with $\mathrm{Cu}^{\mathrm{II}}$ are well characterised, but no studies by electron paramagnetic spectroscopy (EPR) have been reported to date on $\mathrm{Cu}^{\mathrm{II}}$ complexes with the tri- and tetraaza-polyphosphonate ligands. Furthermore, even though there is a reported EPR study on the $\mathrm{Cu}^{\mathrm{II}} / \mathrm{DOTA}$ system, ${ }^{[8]}$ the effect of the $\mathrm{pH}$ on

[a] Centro de Neurociências da Universidade de Coimbra, and Dep. Bioquímica, Faculdade de Ciências e Tecnologia, Universidade de Coimbra,

Ap. 3126, P-3049 Coimbra, Portugal

[b] Centro de Neurociências da Universidade de Coimbra,

Unidade I D "Química-Física Molecular", Faculdade de Ciências e Tecnologia, Universidade de Coimbra,

P-3049 Coimbra, Portugal

[c] CEQUP/Dep. Química, Faculdade de Ciências, Universidade do Porto,

P-4169-007 Porto, Portugal<smiles>O=C(O)CN1CCN(C(=O)O)CCN(C(=O)OCc2ccccc2)CC1</smiles>

NOTA

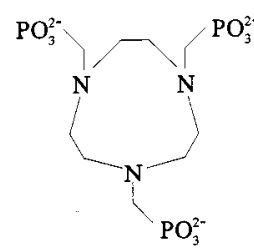

NOTP
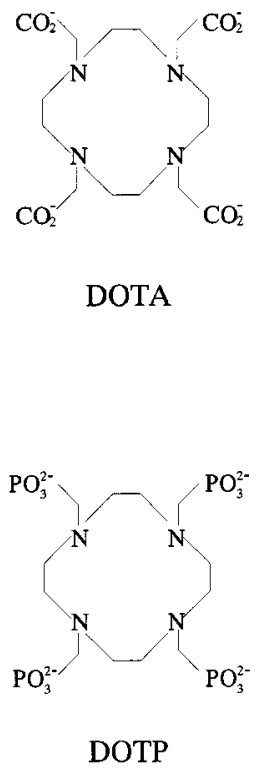

Figure 1. Schematic representation of the macrocyclic ligands investigated in this work

the EPR pattern of these macrocyclic complexes in aqueous solution was never investigated.

The solid-state structures of $\mathrm{Cu}^{\mathrm{II}}$ complexes with NOTA, ${ }^{[9]}$ NOTP, ${ }^{[10]}$ DOTA, ${ }^{[11]}$ and analogous tetraazamacrocyclic ligands, ${ }^{[12-20]}$ have been obtained by X-ray diffractrometry. The NOTA complex in $\mathrm{Na}[\mathrm{Cu}(\mathrm{NOTA})] \cdot 2 \mathrm{NaBr} \cdot 8 \mathrm{H}_{2} \mathrm{O}$ was found to have a distorted pseudoprismatic geometry, with the metal ion bound to all donor atoms of the ligand (three carboxylate oxygen atoms and three ring nitrogen atoms). ${ }^{[9]}$ In the methylenephosphonate analogue $\mathrm{Cu}^{\mathrm{II}} / \mathrm{NOTP}$ the metal ion is bound to only two oxygen atoms from the pendant arms of the macrocycle and to the three ring nitrogen atoms in a dis- 
torted square-pyramidal structure; the axial position is occupied by a ring nitrogen atom, for which the usual long axial $\mathrm{Cu}-\mathrm{N}$ bond length is observed. ${ }^{[10]}$

In the mononuclear $\mathrm{Cu}^{\mathrm{II}}$ complex with the tetraaza ligand DOTA, the metal ion exists in a distorted octahedral geometry, coordinated to all ring nitrogen atoms and to two (opposite) carboxylate oxygen atoms; the other two carboxylate groups are protonated. ${ }^{[1]}$ The two coordinated oxygen and two nitrogen atoms (in the trans positions in the macrocycle) occupy the equatorial positions, while the other two nitrogen atoms are axially bound. The axial bonds are elongated, as expected from the Jahn-Teller effect, but this elongation is not as pronounced as in other copper(II) complexes, probably as a consequence of steric constraints imposed by the cyclic structure of the ligand.

The stability constants in aqueous solution (at $298 \mathrm{~K}$ ) of copper(II) complexes with polyaza ligands have been determined by several authors: NOTA, $\log K_{\mathrm{ML}}=21.63(1 \mathrm{M}$ $\left.\mathrm{NaClO}_{4}\right){ }^{\left[{ }^{[21]}\right.}$ DOTA, $\log K_{\mathrm{ML}}=22.25[0.1 \mathrm{M}$ $\left.\left(\mathrm{CH}_{3}\right)_{4} \mathrm{NNO}_{3}\right],{ }^{[22-24]} 22.72(0.1 \mathrm{M} \mathrm{KCl}) ;{ }^{[25]} \mathrm{NOTP}, \log K_{\mathrm{ML}}=$ $21.3\left(1 \mathrm{M} \mathrm{KNO}_{3}\right){ }^{\text {[26] }}{ }^{[20 T P}, \log K_{\mathrm{ML}}=25.4\left(1 \mathrm{M} \mathrm{KNO}_{3}\right){ }^{[27]}$ The presence of protonated species in aqueous solution $\left(\mathrm{MH}_{n} \mathrm{~L}, n\right.$ is typically 1 or 2$)$, along with the more stable nonprotonated form (ML), has been detected for some $\mathrm{Cu}^{\mathrm{II}}$ macrocyclic chelates. ${ }^{[25,28,29]}$ Although the formation of binuclear complexes $\left(\mathrm{M}_{2} \mathrm{~L}\right)$ has been observed in some cases in the solid state, ${ }^{[23]}$ it appears to be negligible in solution. ${ }^{[20-22]}$

Most of the $\mathrm{Cu}^{\mathrm{II}}$ tri- and tetraazamacrocyclic complexes present in aqueous solution are thus mononuclear and fiveor six-coordinate, with the metal ion probably bound to all the nitrogen atoms of the macrocyclic ring and to two or three carboxylate oxygens of its pendant arms. These $\mathrm{Cu}^{\mathrm{II}}$ complexes often display strong tetragonal distortions that normally result in a lengthening of the axial metal-ligand bonds and an associated compression of the four equatorial ones.

In the present work, $\mathrm{Cu}^{\mathrm{II}}$ complexes with the polyazapolycarboxylate ligands NOTA and DOTA, and with the polyazapolymethylenephosphonate macrocycles NOTP and DOTP were studied in aqueous solution at different $\mathrm{pH}$ values and in the presence of distinct electrolytes, by electronic absorption spectrophotometry (visible region) and electron paramagnetic resonance spectroscopy (EPR). Whilst these techniques are not especially good indicators of the geometry of the copper(II) complexes, by taking into account the known solid-state structures of the NOTA, DOTA, and NOTP complexes, and those of other closely related compounds, it was possible to get some insight into the solution behaviour of these systems. ${ }^{[30][32]}$

\section{Results and Discussion}

\section{Visible Spectrophotometry}

The electronic absorption spectra (visible region) of the complexes studied exhibit an asymmetric band in the wave-
Table 1. Electronic transitions (visible region) for several $\mathrm{Cu}^{\mathrm{II}}$ complexes with some polyazapoly-carboxylate/polymethylenephosphonate macrocycles, in aqueous solution at $\mathrm{pH}$ 7.0. The experiments were run at $298 \mathrm{~K}$, for a sample concentration of $4 \cdot 10^{-3}$ $\mathrm{mol} \cdot \mathrm{dm}^{-3}$

\begin{tabular}{ll}
\hline Complex & $\begin{array}{l}\left.\lambda_{\max }, \mathrm{nm}^{3} \cdot \mathrm{dmol}^{-1} \cdot \mathrm{cm}^{-1}\right) \\
\end{array}$ \\
\hline $\mathrm{Cu}\left(\mathrm{H}_{2} \mathrm{O}\right)_{6}{ }^{2+}{ }^{2 \mathrm{a}]}$ & $833(13)$ \\
$\mathrm{Cu} / \mathrm{NOTA}^{2}$ & $750(75)$ \\
& $750(72.2)^{[\mathrm{cc}]}$ \\
$\mathrm{Cu} /$ DOTA & $740(95)$ \\
& $734(100)^{[\mathrm{b}]}$ \\
$\mathrm{Cu}(\mathrm{NOTP})^{4-}$ & $680(110)$ \\
$\mathrm{Cu}(\text { DOTP })^{6-}$ & $640(625)$ \\
\hline${ }^{[\mathrm{a}] \text { See ref. }}{ }^{[33]}-{ }^{[\mathrm{b}]}$ See ref. ${ }^{[8]}, \mathrm{pH}=9.0,298 \mathrm{~K} .-{ }^{[\mathrm{c}]}$ See ref. ${ }^{[9]}$, \\
pH $=1.0-10.0,298 \mathrm{~K}$.
\end{tabular}

length region between 500 and $850 \mathrm{~nm}$ (Table 1), with molar absorptivity coefficients that are typical of $d-d$ transitions in highly symmetric $\mathrm{Cu}^{\mathrm{II}}$ complexes with tetragonal Jahn-Teller distortion. ${ }^{[33]}$ The cyclic nature of these chelating ligands, however, imposes limits on the extent of this distortion, and the difference in length between the axial and equatorial bonds to copper is smaller in $\mathrm{Cu}^{\mathrm{II}}$ triaza and tetraazamacrocyclic chelates than in $\mathrm{Cu}^{\mathrm{II}}$ complexes with noncyclic ligands. ${ }^{[34]}$

Cu/NOTA: Previous potentiometric and spectroscopic studies $^{[21]}$ have shown that two distinct complex species are present in aqueous solution. In the $\mathrm{pH}$ range 2.0 to 2.5 , $[\mathrm{Cu}(\mathrm{HNOTA})]$ is present at concentrations higher than $60 \%$ of total copper, while for $\mathrm{pH}$ values above 3.5 the predominant form is [Cu(NOTA) $]^{-}$. These complexes exhibit different spectra: that of $[\mathrm{Cu}(\mathrm{HNOTA})]$ has a $d-d$ band at $660 \mathrm{~nm}$, which is bathochromically shifted to $750 \mathrm{~nm}$ in the deprotonated species. ${ }^{[21]}$ The solid state geometry of $\mathrm{Na}[\mathrm{Cu}(\mathrm{NOTA})] \cdot 2 \mathrm{NaBr} \cdot 8 \mathrm{H}_{2} \mathrm{O}$ is intermediate between pure octahedral and trigonal prismatic, and a distortion from octahedral geometry is expected to cause a decrease in ligand field strength and thus an increase in $\lambda_{\max }$. Protonation of one of the carboxylate groups, and subsequent substitution by a solvent molecule, is accompanied by either a release of strain or a reorientation of the metal-to-ligand bonds, which leads to an increase in ligand field strength and thus explains the high energy for the $d-d$ band in $[\mathrm{Cu}(\mathrm{HNOTA})]$. These observations suggest that the ligand is five-coordinate in acidic solutions, but six-coordinate at high $\mathrm{pH}$.

Cu/DOTA: Several copper complexes are present in solution: in the $\mathrm{pH}$ range 2.4 to 3.2 , the fully protonated $\left[\mathrm{Cu}\left(\mathrm{H}_{2} \mathrm{DOTA}\right)\right]$ complex is the most abundant, but at higher $\mathrm{pH}[\mathrm{CuHDOTA}]^{-}$and $[\mathrm{Cu}(\mathrm{DOTA})]^{2-}$ are also present in significant amounts, the former reaching its maximum concentration (ca. $30 \%$, based on total $\mathrm{Cu}^{\mathrm{II}}$ concen-

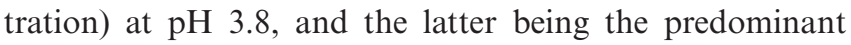
form at $\mathrm{pH}$ higher than 4.6. However, the spectra now obtained were found to be insensitive to $\mathrm{pH}$ changes, thus suggesting that protonation does not impose severe structural changes in the coordination sphere. As the molecular struc- 
ture of $\left[\mathrm{Cu}\left(\mathrm{H}_{2} \mathrm{DOTA}\right)\right]^{[11]}$ reveals two nonbound carboxylate groups, deprotonation of these distant nonbonding carboxylate groups is not expected to exert a marked influence in the electronic structure of the metal complex. The spectrum of the crystalline form has one $d-d$ band centred at $715 \mathrm{~nm},{ }^{[11]}$ a value quite similar to that found in solution (Table 1); the small difference in band maxima is most probably due to solvation or solid-state effects. It should be noted that the energy of this $d-d$ band is lower than that usually found for copper(II) complexes with tetragonally distorted octahedral geometry and an $\mathrm{N}_{2} \mathrm{O}_{2}$ equatorial plane. Nevertheless, the crystal structure shows that the tetragonal distortion is unusually small in this complex, ${ }^{[11]} \mathrm{a}$ consequence of the conformation adopted by the ligand, and this is expected to cause a decrease in the equatorial ligand field and thus in the energy of the $d-d$ band. The similarity in the values of $\lambda_{\max }$ in the solid and in solution suggests that the ligand is mainly six-coordinate in solution.

Cu/NOTP: The band detected in the spectrum appears at energies similar to those of $[\mathrm{Cu}(\mathrm{HNOTA})]^{[21]}$ and $\left[\mathrm{Cu}\left([9] \mathrm{aneN}_{3}\right)\left(\mathrm{H}_{2} \mathrm{O}\right)_{3}\right]^{2+}$ in aqueous solution, ${ }^{[21,35]}$ implying that the coordination mode of this macrocyclic polyphosphonate ligand is different from that of the similar complex, $[\mathrm{Cu}(\mathrm{NOTA})]^{-}$. This is in accordance with the crystal structure reported for the NOTP complex, in which one of the phosphonate groups is not bound to the metal centre. ${ }^{[10]}$ The distinct coordination behaviour of NOTP and NOTA may be attributed to their different charges. In fact, in $\mathrm{Cu} /$ NOTP a very high negative charge would be localised at the metal centre should the three available phosphonate groups bind to $\mathrm{Cu}^{\mathrm{II}}$, and thus NOTP is five-coordinate here.

Cu/DOTP: In this complex, the four nitrogen atoms of the cyclic structure are expected to be involved in bonding, leaving only two coordination sites of the metal centre available, either for pendant phosphonate groups or for solvent molecules. The spectra of the complexes with DOTP are significantly different from those with DOTA, implying distinct structures for these complexes in solution. However, the $d-d$ band for Cu/DOTP is in the same energy range as that of the corresponding copper(II) complex with the ligand [12] $\mathrm{aneN}_{4}$, which has a square-pyramidal geometry in solution, with the four ring nitrogen atoms defining the equatorial plane and one axial position occupied by a solvent molecule. ${ }^{[36]}$ The present results support a similar structure for the $\mathrm{Cu} / \mathrm{DOTP}$ complex, in which the axial position of the pyramid is probably occupied by an oxygen from one phosphonate side-arm, in analogy with the solid state geometry reported for the copper(II) complex with the similar ligand $N, N$, $N$ ', $N$,"'-tetrakis(2-diphenylphosphorylethyl)-1,4,7,10-tetraazacyclododecane. ${ }^{[37]}$

\section{EPR Spectroscopy}

The EPR spectra of frozen aqueous solutions $(77 \mathrm{~K})$ of the complexes under study are shown in Figures 2 and 3, and the corresponding anisotropic parameters are summarised in Table 2.
Cu/NOTA: The EPR spectrum of Cu/NOTA at $\mathrm{pH} 7$ shows two different signals, corresponding to two distinct $\mathrm{Cu}^{\mathrm{II}}$ complex species, in a $3: 2$ concentration ratio (Figure $2 \mathrm{~A}$, Table 2). Both signals are typical of $\mathrm{Cu}^{\mathrm{II}}$ complexes in a tetragonal ligand field, with a $d\left(x^{2}-y^{2}\right)$ ground state. ${ }^{[30]}$ In order to check if the two species detected are $\mathrm{pH}$ dependent, EPR spectra were also recorded at $\mathrm{pH} 3$ and $\mathrm{pH}$ 9. In alkaline solution the spectrum is identical to the one at $\mathrm{pH} \mathrm{7,} \mathrm{thus} \mathrm{excluding} \mathrm{the} \mathrm{formation} \mathrm{of} \mathrm{hydroxo-com-}$ plexes in this $\mathrm{pH}$ region. Under acidic conditions, however, it is possible to perceive at least one more $\mathrm{Cu}^{\mathrm{II}}$ signal superimposed on the two signals observed at $\mathrm{pH} 7$. Based on the stability constants reported in the literature ${ }^{[21]}$ the additional signal detected at $\mathrm{pH} 3$ must be due to $[\mathrm{Cu}(\mathrm{H}-$ NOTA)], while the other two signals observed in all the samples studied probably reflect the presence of two geometric isomers for $[\mathrm{Cu}(\mathrm{NOTA})]^{-}$. Simulation of the spectrum obtained at $\mathrm{pH} 3$ was unsuccessful, due to its poor resolution and to the existence of at least three different signals. To try to improve resolution, spectra were obtained in the presence of inert electrolytes: $\mathrm{NaCl}(1 \mathrm{M}), \mathrm{NaClO}_{4}$ $(0.1$ and $1 \mathrm{M})$, and $\left(\mathrm{CH}_{3}\right)_{4} \mathrm{NNO}_{3}(0.1 \mathrm{M})$; however, no significant differences were obtained, either in resolution or in the overall signal pattern.

Several hypotheses concerning the occurrence of two isomeric forms of $[\mathrm{Cu}(\mathrm{NOTA})]^{-}$, excluding protonation equilibria, may be advanced, but the large difference between the $g_{\|}$and $A_{\|}$values of the two signals observed at $\mathrm{pH} 7$ clearly points to different coordination environments. The signal with $\mathrm{g}_{\|}=2.287$ and $\mathrm{A}_{\|}=149.5 \cdot 10^{-4}$ $\mathrm{cm}^{-1}$ is typical of a six-coordinate complex with a distorted octahedral structure similar to that observed in the solid state. ${ }^{[9]}$ The smaller $\mathrm{g}_{\|}$and larger $\mathrm{A}_{\|}$values of the other signal, in turn, point to a significant decrease in the axial ligand field for the second isomer. This decrease in axial interaction may be caused either by substitution of one axial ligand by a solvent molecule, or simply by breaking of an axial ligand bond with formation of a five-coordinate square-pyramidal structure. The latter hypothesis is supported by the similarity between the EPR parameters of the system under discussion and those of $\mathrm{Cu}^{\mathrm{II}}$ square-pyramidal complexes with the macrocyclic ligands [12] ane $\mathrm{N}_{4},{ }^{[36]}$ 1,4,7,10-tetrabenzyl-2,5,8,11-tetraethyl-1,4,7,10-tetraazacyclododecane ${ }^{[39]}$ and 7,11-bis(carboxymethyl)-1,4-dioxa-7,11-diazacyclotridecane. ${ }^{[40]}$

Cu/DOTA: The EPR spectrum of $[\mathrm{Cu}(\mathrm{DOTA})]^{2-}$ in aqueous solution was previously obtained by other authors at $\mathrm{pH} 9$ for a metal-to-ligand ratio of $1: 2,{ }^{[8]}$ and the reported parameters are included in Table 2. The spectra obtained in the present work for a metal-to-ligand ratio of $1: 1$ and at $\mathrm{pH} 3,7$, and 9, are poorly resolved both at room temperature and in frozen solution $(77 \mathrm{~K})$. In order to improve spectral resolution several different electrolytes were added to the solutions; however, it was found that those electrolytes containing $\mathrm{Na}^{+}$interact with the copper(II) complexes studied (see below).

At $\mathrm{pH} 3$ and in the absence of $\mathrm{Na}^{+}$ions, the spectra obtained either without electrolyte or in the presence of 
Table 2. EPR parameters (X-band, $0.34 \mathrm{~T}, 9.5 \mathrm{GHz}$ ) for the $\mathrm{Cu}^{\mathrm{II}}$ complexes with the polyazamacrocycles NOTA, DOTA, NOTP, and DOTP, in aqueous frozen solution $(77 \mathrm{~K})$, at $\mathrm{pH} 3.0$ and 7.0

\begin{tabular}{|c|c|c|c|c|c|c|c|c|}
\hline Complex ${ }^{[a]}$ & $\mathrm{pH}$ & & $\mathrm{g}_{\|}^{[\mathrm{b}]}$ & $\mathrm{g}_{\perp}{ }^{[\mathrm{b}]}$ & $\mathrm{A}_{\|}\left(\times 10^{4}\right)\left(\mathrm{cm}^{-1}\right)$ & $\mathrm{A}_{\perp}\left(\times 10^{4}\right)\left(\mathrm{cm}^{-1}\right)^{[\mathrm{a}, \mathrm{b}]}$ & $\kappa_{\|}^{[c]}$ & $\begin{array}{l}\text { Population } \\
(\%)^{[a]}\end{array}$ \\
\hline $\mathrm{Cu} / \mathrm{NOTA}$ & $7.0^{[\mathrm{d}]}$ & & 2.2332 .287 & 2.0512 .063 & $\begin{array}{l}179.0 \\
1495\end{array}$ & 30.0 & 0.46 & $\begin{array}{l}60 \\
40\end{array}$ \\
\hline \multirow[t]{2}{*}{$\mathrm{Cu} / \mathrm{DOTA}$} & 9.0 & & $2.300^{[\mathrm{e}]}$ & $2.062^{[\mathrm{e}]}$ & $150.3^{[\mathrm{e}]}$ & & & \\
\hline & $\begin{array}{l}7.0 \\
3.0^{[\mathrm{d}]} \\
7.0^{\mathrm{d}]}\end{array}$ & $\begin{array}{l}\text { no electrolyte } \\
\mathrm{Na}^{+}(1 \mathrm{M}) \\
\mathrm{Na}^{+}(1 \mathrm{M})\end{array}$ & $\begin{array}{l}2.300 \\
2.278 \\
2.241 \\
2.301\end{array}$ & $\begin{array}{l}2.070 \\
2.063 \\
2.061 \\
2.058\end{array}$ & $\begin{array}{l}150.0 \\
169.0 \\
157.2 \\
150.0\end{array}$ & $\begin{array}{l}<5 \\
15.0 \\
10.0\end{array}$ & $\begin{array}{l}- \\
0.49 \\
0.61\end{array}$ & $\begin{array}{l}100 \\
80 \\
20\end{array}$ \\
\hline $\mathrm{Cu} / \mathrm{NOTP}$ & 7.0 & & 2.265 & 2.062 & 160.0 & 4.9 & 0.58 & - \\
\hline $\mathrm{Cu} / \mathrm{DOTP}$ & 7.0 & & 2.210 & 2.035 & 165.0 & 4.4 & 0.49 & - \\
\hline
\end{tabular}

[a] The experiments were run for a sample concentration of $1 \cdot 10^{-3} \mathrm{M}$. The reported values were obtained by simulation of the experimental spectra. - $\left.{ }^{\mathrm{b}}\right]^{\prime}$ Approximate value, as only one band is detected in this region of the spectrum. - ${ }^{[\mathrm{c}]}$ Calculated values using the spin-orbit coupling constant of the free $\mathrm{Cu}^{\mathrm{II}}$ ion $\left(-829 \mathrm{~cm}^{-1}\right)$ (ref. $\left.{ }^{[38]}\right)$ and the energy of the electronic transition band observed for each complex. [d] Two different complexes in solution. - ${ }^{\text {e] }}$ From ref. ${ }^{[8]}, 9.28 \mathrm{GHz}, \mathrm{pH} 9$.

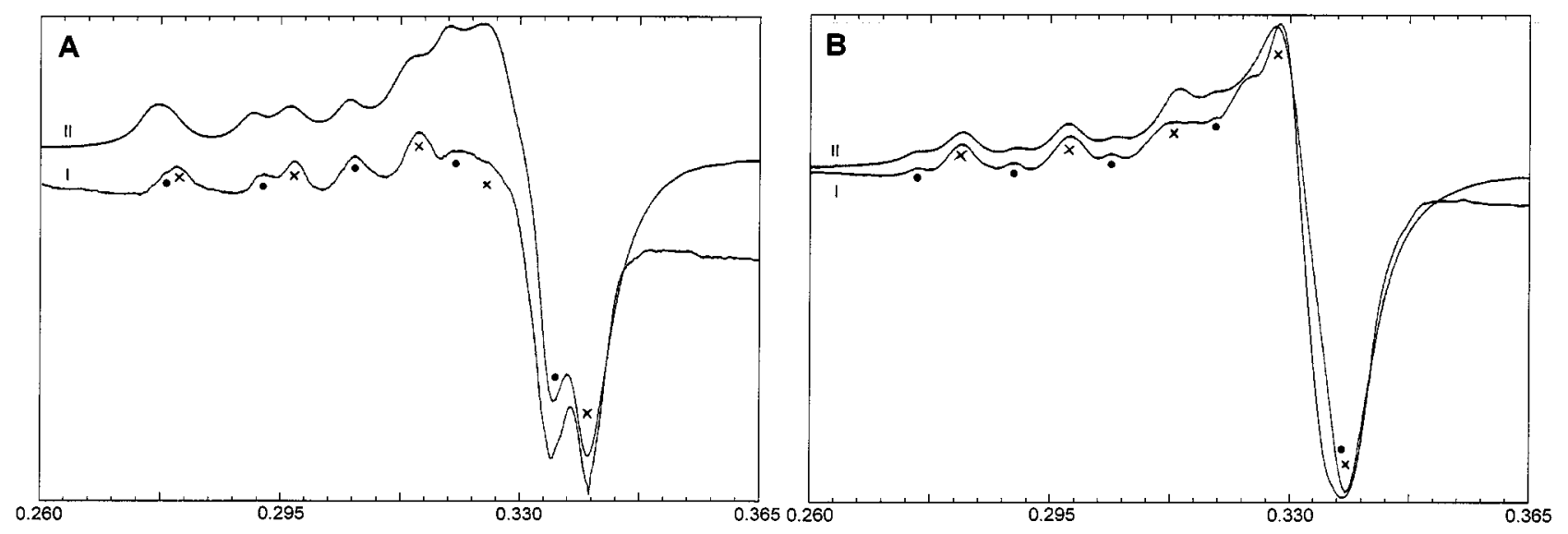

Figure 2. EPR spectra (X-band, $0.34 \mathrm{~T}, 9.5 \mathrm{GHz})$, at $77 \mathrm{~K}$, of the $\mathrm{Cu}^{\mathrm{II}}$ complexes $(1: 1)$ with the macrocyclic polyaza-polycarboxylate ligands NOTA (A) and DOTA (B), in aqueous solution at $\mathrm{pH} 7$, in the presence of $1 \cdot 10^{-1} \mathrm{M} \mathrm{Na}^{+}$: I - Experimental spectra; II Simulated spectra; [complexes] $=1 \cdot 10^{-3} \mathrm{M}$; the symbols $\times$ and $\bullet$ refer to the major and minor complex species of each of the systems studied, respectively

$\left(\mathrm{CH}_{3}\right)_{4} \mathrm{NNO}_{3}(0.5 \mathrm{M})$ exhibit more than one signal but, due to their low resolution, no accurate EPR parameters could be obtained. Addition of $\mathrm{NaClO}_{4}$ or $\mathrm{NaCl}$ caused significant spectral changes, namely the appearance of a new EPR signal superimposed on those observed for solutions without added electrolyte, and for $\left[\mathrm{Na}^{+}\right] \geq 1 \mathrm{M}$ only this new signal was observed (see Figure 3 ).

Similar experiments were carried out for solutions at $\mathrm{pH}$ 7 and $\mathrm{pH} \mathrm{9,} \mathrm{but} \mathrm{since} \mathrm{the} \mathrm{results} \mathrm{obtained} \mathrm{were} \mathrm{identical}$ for these two $\mathrm{pH}$ values they will be discussed together. In the absence of $\mathrm{Na}^{+}$the spectra, although poorly resolved, exhibit only one signal. Addition of $\mathrm{NaCl}$ or $\mathrm{NaClO}_{4}$ induces clear changes in the spectra, with the appearance of a new copper(II) signal (Figure 2B). For these $\mathrm{pH}$ values, however, even for $\left[\mathrm{Na}^{+}\right]=1 \mathrm{M}$, the new signal appears superimposed on the one detected without the electrolyte. The difference in EPR parameters for the two signals observed in solutions containing $\mathrm{Na}^{+}$is significant enough to indicate that the corresponding species have distinct coordination environments, thus implying that in the presence of high concentrations of $\mathrm{Na}^{+}$the $\mathrm{Cu}$ /DOTA complex undergoes a structural reorganisation.

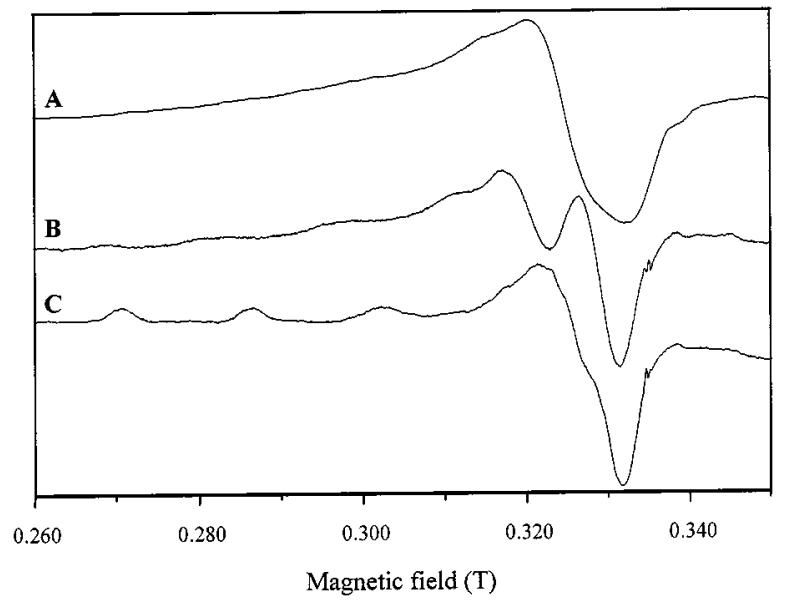

Figure 3. EPR spectra (X-band, 0.34 T, 9.5 GHz), at $77 \mathrm{~K}$, of the $\mathrm{Cu}^{\mathrm{II}}$ complex (1:1) with the macrocyclic polyaza-polycarboxylate ligand DOTA, in aqueous solution at $\mathrm{pH} 3$, as a function of the concentration of $\mathrm{Na}^{+}$ion: $\mathrm{A}-\left[\mathrm{Na}^{+}\right]=0 ; \mathrm{B}-\left[\mathrm{Na}^{+}\right]=1 \cdot 10^{-1} \mathrm{M}$; $\mathrm{C}-\left[\mathrm{Na}^{+}\right]=1 \mathrm{M}$; [complex $]=1 \cdot 10^{-3} \mathrm{M}$

Analysis of the EPR parameters obtained in this work can yield additional information about the interaction of 
the $\mathrm{Cu} /$ DOTA complex with $\mathrm{Na}^{+}$. The signal obtained without added electrolyte at $\mathrm{pH} 7$ was found to have unusual EPR parameters $\left(\mathrm{g}_{\perp}=2.10, \mathrm{~g}_{\|}=2.30\right.$ and $\mathrm{A}_{\|}=$ $150 \cdot 10^{-4} \mathrm{~cm}^{-1}$ ) for a tetragonally distorted octahedral chelate with a $\mathrm{N}_{2} \mathrm{O}_{2}$ equatorial plane, namely high $\mathrm{g}_{\|}$and low $\mathrm{A}_{\|}$values. These values can be accounted for by taking into consideration the crystallographic structure of this system, ${ }^{[11]}$ that shows a small tetragonal distortion compared to what is usually found in other copper(II) complexes. A decrease in tetragonal distortion is expected to increase $\mathrm{g}_{\|}$ and decrease $A_{\|}$, and also to decrease the anisotropy of the EPR spectra. ${ }^{[24]}$ Thus, it is quite reasonable to assume that the spectrum observed at $\mathrm{pH} 7$ without added $\mathrm{Na}^{+}$is due to $[\mathrm{Cu}(\mathrm{DOTA})]^{2-}$, with a geometry similar to that observed in the solid state.

The new signals observed in the solutions containing $\mathrm{Na}^{+}$, at both $\mathrm{pH} 3$ and 7 are not significantly different. Comparison of the corresponding EPR parameters with those obtained from the spectrum at $\mathrm{pH} 7$ in the absence of $\mathrm{Na}^{+}$shows that these new species have significantly lower $\mathrm{g}_{\|}$and higher $\mathrm{A}_{\|}$values. These values are similar to those commonly found for six-coordinate copper(II) complexes displaying a $\mathrm{N}_{2} \mathrm{O}_{2}$ equatorial plane. This seems to imply that these new complexes have a different structure, for which the steric constraints that impose a low axial distortion to copper coordination in $[\mathrm{Cu}(\mathrm{DOTA})]^{2-}$ have been lost. This may be attributed either to partial solvolysis of $[\mathrm{Cu}(\mathrm{DOTA})]^{2-}$ or to a rearrangement of the ligand around the metal, leading to a distinct coordination pattern. This structural reorganisation induced by $\mathrm{Na}^{+}$points to a strong interaction between the alkali metal ion and the copper(II) complex, either (a) by binding to the ligand free acetate groups, or (b) by competition of the sodium ions with $\mathrm{Cu}^{\mathrm{II}}$ for the coordinated acetate side-arms.

A precedent for the former hypothesis is provided by noting that $\mathrm{Na}^{+}$binds to the free ligand $\left(\log K_{\mathrm{Na} / \text { DOTA }}=4.38\right.$, $\left.\left[\left(\mathrm{CH}_{3}\right)_{4} \mathrm{NNO}_{3}\right]=0.1 \mathrm{M}\right) .{ }^{[16]}$ However, against this it should be noted that if $\mathrm{Na}^{+}$only interacts significantly with the free acetate groups of the complex, its effect would be more important for negatively charged species; it was found that at $\mathrm{pH} 7$ and $\left[\mathrm{Na}^{+}\right]=1 \mathrm{M}$, where the predominant complex species would have a -2 charge, the presence of $[\mathrm{Cu}(\mathrm{DOTA})]^{2-}$ is still detected, while at $\mathrm{pH} 3$, where the $\mathrm{Cu}^{\mathrm{II}}$ complexes are expected to be protonated, either neutral or with a +1 charge, only the signal due to the $\mathrm{Na}^{+} / \mathrm{Cu} / \mathrm{DOTA}$ complex was observed. Our results thus seem to support the second hypothesis, despite the large stability constants in aqueous solution of these $\mathrm{Cu}^{\mathrm{II}}$ macrocyclic chelates. The observed $\mathrm{pH}$ dependence for the formation of $\mathrm{Na}^{+} / \mathrm{Cu} / \mathrm{DOTA}$ complexes may result from the lower stability of the protonated complexes, due to the smaller negative charge of the protonated ligand, which favours the release of at least one acetate group which would promptly bind to $\mathrm{Na}^{+}$. It is worth noting, however, that the EPR signals detected at pH 3 and 7 (Figure 2 and Figure 3) in the presence of $\mathrm{Na}^{+}$are slightly different, which implies that they are not due to identical species but to structurally very similar complexes. These small differences are probably a consequence of differing degrees of protonation of the complex.
Analysis of the EPR parameters for the $\mathrm{Na}^{+} / \mathrm{Cu} / \mathrm{DOTA}$ system show that these new complexes seem to have very different structures to that of $[\mathrm{Cu}(\mathrm{DOTA})]^{2-}$ in the solid state, an observation that also favours the hypothesis of release of at least one of the carboxylate pendant arms of the macrocyclic ligand, either yielding a five-coordinate complex or merely leading to substitution by a solvent molecule in the coordination sphere of the metal ion. In either case, breaking of one $\mathrm{M}-\mathrm{O}$ (carboxylate) bond would release some of the steric strain imposed by the ligand, as present in the solid state, which would facilitate decoordination.

Cu/NOTP and Cu/DOTP: The frozen solution EPR spectra of $\mathrm{Cu} / \mathrm{NOTP}$ and $\mathrm{Cu} / \mathrm{DOTP}$ at $\mathrm{pH} 7$ reflect the axial symmetry of these systems (with $\mathrm{g}_{\|}>\mathrm{g}_{\perp}$ ). Hyperfine structure due to the copper nuclei $\left({ }^{63} \mathrm{Cu}\right.$ and ${ }^{65} \mathrm{Cu}, I=3$ / 2 ) is detected in the parallel region (Table 2), whereas the perpendicular region is not sufficiently resolved to allow the observation of any such splitting. These data are typical of $\mathrm{Cu}^{\mathrm{II}}$ complexes in a tetragonal field, with a $d\left(x^{2}-y^{2}\right)$ ground state. ${ }^{[24]}$ The band patterns at $\mathrm{pH} 3,7$, and 9 are very similar, which indicates that protonation of these complexes does not induce significant structural or electronic changes. This observation may be taken as an indication that protonation of these systems probably takes place at the unbound phosphonate side-arms.

The influence of added electrolytes $\left[\mathrm{NaCl}, \mathrm{NaClO}_{4}\right.$, and $\left.\left(\mathrm{CH}_{3}\right)_{4} \mathrm{NNO}_{3}\right]$ was also checked, but no appreciable changes in the EPR spectra were detected, either in the overall signal pattern or in band width.

Based on the spectrophotometric results discussed above, a trans coordination of DOTP to the metal centre has been proposed, implying an $\mathrm{N}_{4}$ equatorial plane. The EPR parameters obtained for this system support that hypothesis, although the $\mathrm{g}_{\|}$value is higher, and the $\mathrm{A}_{\|}$value smaller, than typical values found for other complexes with this coordination environment. These differences, however, may be a consequence of a strong axial bond with the oxygen atom of a phosphonate side-arm, similar to the one reported for the related complex with $N, N^{\prime}, N^{\prime \prime}, N^{\prime}$ "'-tetrakis(2-diphenylphosphorylethyl)-1,4,7,10-tetraazacyclododecane. ${ }^{[37]}$

For $\mathrm{Cu} / \mathrm{NOTP}$, the $\mathrm{g}_{\|}$value is larger than that of DOTA, in agreement with the $\mathrm{N}_{2} \mathrm{O}_{2}$ equatorial plane expected for this complex. As in Cu/DOTP, the $\mathrm{A}_{\|}$value is smaller than expected for a square-pyramidal structure. This may also be rationalised by a strong axial metal-ligand interaction, since a low tetragonal distortion is expected in this case due to the facial coordination of the cycle, which imposes a short axial bond to the nitrogen atom.

\section{Conclusion}

One important result that emerged from the present study is that the polyphosphonate ligands NOTP and DOTP always coordinate to copper(II) in a pentadentate mode, although the corresponding complexes may be fiveor six-coordinate by binding a solvent molecule. This behaviour is to be contrasted with that of the polycarboxylate 
ligands NOTA and DOTA, which is more complex. Firstly, the coordination mode of the ligands was found to be $\mathrm{pH}$ dependent: (a) in copper(II) complexes with NOTA the ligand is five-coordinate in acidic solutions, through protonation of one carboxylate group, but at $\mathrm{pH} 7$ two complexes were observed in solution, probably with the ligand being six- and five-coordinate; (b) in those complexes with DOTA, the ligand is essentially six-coordinate, although at low $\mathrm{pH}$ the possibility of protonation of one bound carboxylate group could not be ruled out. Secondly, the DOTA coordination mode was also found to be dependent on the presence of sodium ions in solution, which are capable of competing with $\mathrm{Cu}^{\mathrm{II}}$ for coordinating carboxylates; in fact, with $\left[\mathrm{Na}^{+}\right]=1 \mathrm{M}$ and at $\mathrm{pH} 3$ only complexes in which DOTA acts as a five-coordinate ligand could be detected by EPR, whereas at $\mathrm{pH} 7$, two species - displaying a sixcoordinate and five-coordinate DOTA - were observed. Once the presence of sodium ions was found not to affect the coordination equilibria of the other three macrocyclic ligands, it is likely that the steric constraint imposed by DOTA when acting in a six-coordinate mode eases by decoordination of one carboxylate group when in the presence of a large excess of sodium ions.

\section{Experimental Section}

General: The ligands were synthesised and purified as described elsewhere (NOTA, ${ }^{[41]}$ DOTA, ${ }^{[23,42]}$ NOTP and DOTP ${ }^{[43,44]}$ ). The purity of the ligands was checked by ${ }^{1} \mathrm{H}-\mathrm{NMR}$ spectroscopy (Varian XL-200 and Varian Unity-500 spectrometers).

Preparation of Copper(II) Complexes: The concentration of the ligand solutions was determined by complexometric titration, using a copper chloride solution and murexide (5,5'-nitrilodibarbituric acid) as an indicator. The copper chloride solution was previously titrated with standard EDTA, with Black Sulphon F [1-hydroxy8-(2-hydroxynaphthylazo)-2-(sulfonaphthylazo)-3,6-disulfonic acid] as an indicator. Stock aqueous solutions of the complexes $\left(1 \cdot 10^{-3}\right.$ M) were prepared by adding stoichiometric amounts of the macrocyclic ligand to a solution of copper chloride (Aldrich). The $\mathrm{pH}$ of the solutions was adjusted with $\mathrm{HCl}$ and $\mathrm{CO}_{2}$-free $\mathrm{NaOH}$ (using a Crison MicropH 2002 pH-meter with an Ingold 405-M5 combined electrode).

Spectroscopic Studies: The electronic spectra (visible region) were obtained in a double beam JASCO-7800 spectrometer (cell with $1 \mathrm{~cm}$ optical path). The experiments were run at $298 \mathrm{~K}$, in the $\mathrm{pH}$ range between 2.0 and 10.0, for sample concentrations of $1 \cdot 10^{-3}$ and $1 \cdot 10^{-5} \mathrm{M}$. No changes in spectra were observed upon repeating the measurements one week after the first run.

The EPR spectra (X-band, $0.34 \mathrm{~T}, 9.5 \mathrm{GHz}$ ), were obtained in a continuous wave BRUKER ESP-300E spectrometer, with a microwave power of $15.9 \mathrm{~mW}$ and a modulation frequency of $100 \mathrm{kHz}$. The experiments were performed at $\mathrm{pH} 3.0,7.0$, and 9.0, both at $298 \mathrm{~K}$ and at $77 \mathrm{~K}$ (frozen samples). DPPH (2,2-diphenyl-1-picrylhydrazil radical) was used as an internal reference $(g=2.0037)$. Simulation of experimental EPR spectra, in order to obtain the corresponding anisotropic parameters, were performed using a modified version of the program developed by Pilbrow. ${ }^{[4]}$ This program assumes a purely Lorentzian shape for the EPR bands, and does not account for changes in signal width with external magnetic field. The simulation was carried out ignoring the isotopic mixture of the copper nuclei and nuclear quadrupole effects.

\section{Acknowledgments}

Financial support from "Fundação para a Ciência e Tecnologia", Portugal, is gratefully acknowledged, through projects Praxis $2 / 2.1 /$ SAU/1194/95 (CG), Praxis 2/2.1/QUI/316/94 (BC), and PBIC/C/ QUI/2219/95 (MPM).

${ }^{[1]}$ M. Studer, T. A. Kaden, H. R. Mäcke, Helv. Chim. Acta 1990, $73,149$.

[2] G. L. DeNardo, G. R. Mirick, L. A. Kroger, R. T. O'Donnell, C. F. Meares, S. J. DeNardo, J. Nucl. Med. 1996, 37, 451.

${ }^{[3]}$ E. L. Hegg, J. N. Burstyn, Inorg. Chem. 1996, 35, 7474.

${ }^{[4]}$ E. L. Hegg, J. N. Burstyn, J. Am. Chem. Soc. 1995, 117, 7015.

[5] S. V. Deshpande, S. J. DeNardo, D. L. Kukis, M. K. Moi, M. J. McCall, G. L. DeNardo, C. F. Meares, J. Nucl. Med. 1990, 31,473 .

${ }^{[6]}$ C. F. G. C. Geraldes, A. D. Sherry, R. D. Brown III, S. H. Koenig, Magn. Res. Med. 1986, 3, 242.

${ }^{[7]}$ K. Kumar, M. F. Tweedle, Pure Appl. Chem. 1993, 65, 515, and refs. therein.

${ }^{[8]}$ R. Delgado, J. J. R. Fraústo da Silva, M. C. T. A. Vaz, Talanta 1986, 33, 285 .

${ }^{[9]}$ K. Wieghardt, U. Bossek, P. Chanduri, W. Herrmann, B. C. Menke, J. Weiss, Inorg. Chem. 1982, 21, 4308.

${ }^{[10]}$ M. Y. Antipin, A. P. Baranov, M. I. Kabachnik, T. Y. Medved', Y. M. Polikarpov, Y. T. Struchkov, B. K. Shcherbakov, Dokl. Akad. Nauk SSSR 1986, 287, 130.

${ }^{[11]}$ A. Riesen, M. Zehnder, T. A. Kaden, Helv. Chim. Acta 1986, 69, 2067.

${ }^{[12]}$ K. Kumar, M. F. Tweedle, M. F. Malley, J. Z. Gougoutas, Inorg. Chem. 1995, 34, 6472 .

${ }^{[13]}$ A. Riesen, M. Zehnder, T. A. Kaden, Helv. Chim. Acta 1986, 69, 2074.

${ }^{[14]}$ R. Clay, P. Murray-Rust, J. Murray-Rust, Acta Cryst. 1979, B35, 1984 .

${ }^{[15]}$ T. Sakurai, K. Kobayashi, A. Hasegawa, S. Tsuboyama, K. Tsuboyama, Acta Cryst. 1982, B38, 107.

${ }^{[16]}$ R. E. DeSimeone, E. L. Blinn, K. F. Mucker, Inorg. Nucl. Chem. Lett. 1980, 16, 23 .

${ }^{[17]}$ K. Kobayashi, T. Sakurai, A. Hasegawa, S. Tsuboyama, K. Tsuboyama, Acta Cryst. 1982, B38, 1154.

${ }^{[18]}$ A. Riesen, M. Zehnder, T. A. Kaden, J. Chem. Soc., Chem. Commun. 1985, 1336.

${ }^{[19]}$ A. Riesen, M. Zehnder, T. A. Kaden, Acta Cryst. 1988, C44, 1740.

${ }^{[20]}$ F. P. Remoortere, F. B. Boer, E. C. Steiner, Acta Cryst. 1975, $B 31,1420$.

${ }^{[21]}$ A. Bevilacqua, R. I. Gelb, W. B. Hebard, L. J. Zompa, Inorg. Chem. 1987, 26, 2699.

${ }^{[22]}$ H. Stetter, W. Frank, Angew. Chem. Int. Ed. Engl. 1976, 15, 686.

${ }^{[23]}$ R. Delgado, J. J. R. Fraústo da Silva, Talanta 1982, 29, 815.

${ }^{[24]}$ S. Chaves, R. Delgado, J. J. R. Fraústo da Silva, Talanta 1992, $39,249$.

${ }^{[25]}$ A. T. Clarke, A. E. Martell, Inorg. Chim. Acta 1991, 190, 27.

${ }^{[26]}$ I. M. Kabachnik, T. Y. Medved', Y. M. Polikarpov, B. K. Shcherbakov, F. I. Bel'skii, E. I. Matrosov, M. P. Pasechnik, Bull. Acad. Sci. USSR 1984, 33, 769.

${ }^{[27]}$ I. M. Kabachnik, T. Y. Medved', F. I. Bel'skii, S. A. Pisareva, Bull. Acad. Sci. USSR 1984, 33, 777.

${ }^{[28]}$ H. Z. Cai, T. A. Kaden, Helv. Chim. Acta 1994, 77,383.

${ }^{[29]}$ E. Hörmann, P. C. Riesen, M. Neuburger, M. Zehnder, T. A. Kaden, Helv. Chim. Acta 1996, 79, 235.

${ }^{[30]}$ B. J. Hathaway, Coord. Chem. Rev. 1983, 52, 87, and refs. therein.

${ }^{[31]}$ D. Kivelson, R. Neiman, J. Chem. Phys. 1961, 35, 149.

[32] J. Peisach, W. E. Blumberg, Arch. Biochem. Biophys. 1974, 165,691 .

${ }^{[33]}$ A. B. P. Lever, Inorganic Electronic Spectroscopy, Elsevier, Amsterdam 1968

${ }^{[34]}$ J. Gazo, I. B. Bersuker, J. Garaj, M. Kabesová, J. Kohout, H. Langfelderová, M. Melník, M. Serátor, F. Valach, Coord. Chem. Rev. 1976, 19, 253.

${ }^{[35]}$ R. Yang, L. J. Zompa, Inorg. Chem. 1976, 15, 1499. 
${ }^{[36]}$ M. C. Styka, R. C. Smierciak, E. L. Blinn, R. E. DeSimone, J. V. Passariello, Inorg. Chem. 1978, 17, 82.

${ }^{[37]}$ M. Y. Antipin, A. P. Baranov, M. I, Kabachnik, S. A. Pisareva, Y. M. Polikarpov, E. I. Sinyasvskaya, Y. T. Struchkov, L. B. Tsimbal, Heteroatom Chem. 1996, 7, 229.

${ }^{[38]}$ A. Abragam, B. Bleaney, Electron Paramagnetic Resonance of Transition Ions (Eds.: W. Marshall, D. H. Wilkinson), Clarendon Press, Oxford 1970.

${ }^{[39]}$ N. Azuma, Y. Kohno, F. Nemoto, Y. Kajirawa, K. Ishizu, T. Takakuwa, S. Tsubayama, K. Tsubayama, K. Kabayashi, T. Sakurai, Inorg. Chim. Acta 1994, 215, 109.
${ }^{[40]}$ S. Chaves, A. Cerva, R. Delgado, Polyhedron 1998, 17, 93.

${ }^{[41]}$ C. F. G. C. Geraldes, M. C. Alpoim, M. P. M. Marques, A. D. Sherry, M. Singh, Inorg. Chem. 1985, 24, 3876

${ }^{[42]}$ J. F. Desreux, Inorg. Chem. 1980, 19, 1319.

${ }^{[43]}$ A. D. Sherry, C. R. Malloy, F. M. H. Jeffrey, W. P. Cacheris, C. F. G. C. Geraldes, J. Magn. Res. 1988, 76, 528.

${ }^{[44]}$ C. F. G. C. Geraldes, A. D. Sherry, W. P. Cacheris, Inorg. Chem. 1989, 28, 3336

[45] J. R. Pilbrow, M. E. Winfield, Mol. Phys. 1973, 25, 1073.

Received April 29, 1999 